\title{
Discussion of "Accurate and Efficient Explicit Approximations of the Colebrook Flow Friction Equation Based on the Wright $\omega$-Function" by Dejan Brkić and Pavel Praks, Mathematics 2019, 7, 34; doi:10.3390/math7010034
}

\author{
Majid Niazkar(D) \\ Department of Civil and Environmental Engineering, School of Engineering, Shiraz University, \\ Shiraz 71454, Iran; mniazkar@shirazu.ac.ir
}

Received: 6 February 2020; Accepted: 19 April 2020; Published: 14 May 2020

\begin{abstract}
Estimating the Darcy-Weisbach friction factor is crucial to various engineering applications. Although the literature has accepted the Colebrook-White formula as a standard approach for this prediction, its implicit structure brings about an active field of research seeking for alternatives more suitable in practice. This study mainly attempts to increase the precision of two explicit equations proposed by Brkić and Praks. The results obviously demonstrate that the modified relations outperformed the original ones from nine out of 10 accuracy evaluation criteria. Finally, one of the improved equations estimates closer friction factors to those obtained by the Colebrook-White formula among 18 one-step explicit equations available in the literature based on three of the considered criteria.
\end{abstract}

Keywords: resistance equation; Colebrook-White formula; friction factor; explicit equation; turbulent flow

\section{Introduction}

Brkić and Praks [1] applied Wright $\omega$-Function to improve the accuracy of the estimation of the Colebrook friction factor. As a result, they proposed two new explicit equations using symbolic regression software so called Eureqa. Based on the classification introduced by Niazkar [2], their equations can be categorized as one-step relations for predicting the Darcy-Weisbach friction factor.

This discussion mainly aims to improve the accuracy of the proposed equations by Brkić and Praks [1]. In this regard, the coefficients of the proposed equations are modified using powerful optimization algorithms. Finally, the performances of the original equations and the modified ones were compared with those of other models available in the literature.

\section{Estimating Darcy-Weisbach Friction Factor}

Resistance equations are basically empirical formulas, which play the role of friction forces in both open-channel and pressurized flow fields [3,4]. In essence, coefficients appeared in these equations, invariantly named as resistance coefficients, and are categorized into two groups [4,5]: (1) flow-dependent coefficients and (2) flow-independent coefficients. In this classification, the Darcy-Weisbach friction factor $(f)$ can be considered as one of the latter for laminar, transitional and turbulent regime flows.

Generally, the estimation of $f$ is essential to various engineering applications, like pipe network analysis [6] and water hammer [7]. In addition, this prediction may have impact on the final results 
in numerical modeling. For instance, pipe network analysis requires the calculation of $f$, while the method used for the prediction of $f$ may affect not only the convergence but also the accuracy of final solutions [8]. Furthermore, pipe flows and hydraulic heads are inevitably modified in the process of solving water distribution networks and, consequently, $f$ needs to be revised in each step of pipe network analysis [9]. According to the literature [2], the standard approach to compute $f$ is by solving the Colebrook-White formula presented in Equation (1):

$$
\frac{1}{\sqrt{f}}=-2 \log \left(\frac{\varepsilon}{3.7 D}+\frac{2.51}{\operatorname{Re} \sqrt{f}}\right)
$$

where $\varepsilon$ is absolute pipe-roughness, $D$ is pipe diameter and $R e$ is Reynolds number. Some studies consider 3.71 instead on 3.7 in Equation (1) [1,10,11].

Since Equation (1) is implicit in terms of $f$, several alternative approaches have been suggested for estimating $f[1,2,10-13]$ : (1) graphical approaches like Moody or Rouse diagrams, (2) solving Colebrook-White $(\mathrm{C}-\mathrm{W})$ relation using iterative schemes, (3) explicit approximate relations, (4) Lambert $\mathrm{W}$-function, (5) Wright $\omega$-Function, (6) trial-and-error method, and (7) artificial intelligence models. Among these methods, various studies attempted to develop new accuracy-improved explicit equations; Brkić and Praks' [1] study is one of these efforts as they introduced two new explicit equations, shown in Equations (2) and (3):

$$
\begin{gathered}
f=\left[p_{1}\left(B-C+\frac{p_{2} C}{p_{3}+B+A}\right)\right]^{-2} \\
f=\left[p_{4}\left(B-C+\frac{p_{5} C}{B+A}+\frac{C+p_{6}}{(B+A)^{2}}\right)\right]^{-2}
\end{gathered}
$$

where $p_{i}$ (for $\left.i=1,2,3,4,5,6\right)$ is a constant coefficient, $A=\frac{\operatorname{Re} \varepsilon}{8.0878 D}, B=\ln \left(\frac{\mathrm{Re}}{2.18}\right)$ and $C=\ln (B+A)$. Brkić and Praks [1] determined the values of $p_{i}$ coefficients using Eureqa as the following: $p_{1}=0.8686$, $p_{2}=1.038, p_{3}=0.332, p_{4}=0.8686, p_{5}=1.0119$ and $p_{6}=-2.3849$. Hereafter, Equations (1) and (2) with these coefficients are called Model 1 and Model 2, respectively.

In this comment, the values of $p_{i}$ coefficients were modified using powerful optimization algorithms. The process is descried in Section 3.

\section{Improving the Explicit Equations Proposed by Brkić and Praks}

In order to improve the accuracy of the explicit equations proposed by Brkić and Praks [1], 8000 quasi-Monte Carlo data points generated by the LPTAU51 algorithm [14] were used. Each data point includes one value for three parameters: (1) $\operatorname{Re},(2) \frac{\varepsilon}{D}$ and (3) $f$. The range of these parameters are $4000<\operatorname{Re}<10^{8}, 0<\frac{\varepsilon}{D}<0.05$ and $0.006<f<0.075$, respectively. These ranges were the same as those stated in Brkić and Praks' [1] study. The values of $f$ of these data were obtained by solving the Colebrook-White formula iteratively, while 3.71 was used instead on 3.7 in Equation (1).

The optimum values of $p_{i}$ coefficients of Equations (2) and (3) were achieved by solving optimization problems. The objective functions for improving Equations (2) and (3) were to minimize the root mean square errors and maximum absolute relative errors between the estimated $f$ and the corresponding one from the database, respectively. The only constraint of these optimization problems was to dismiss negative values of $f$. The Modified Honey Bee Mating Optimization (MHBMO) algorithm, which has been successfully applied to various water resources problems [15-17], was exploited to optimize the coefficients of Equation (2). Furthermore, the hybrid MHBMO-Generalized Reduced Gradient (GRG) algorithm, which has been already utilized for solving several water-related problems [18-22], was employed to solve the optimization problem associated with improving Equation (3). The optimized values of $p_{i}$ coefficients of Equations (2) and (3) are: $p_{1}=0.86855, p_{2}=1.03891, p_{3}=0.33623$, $p_{4}=0.86859, p_{5}=1.01151$ and $p_{6}=-2.37718$. In this comment, Equations (1) and (2) with the modified coefficients are called Model 3 and Model 4, respectively. 


\section{Accuracy Evaluation Criteria}

For comparison purposes, the test data used in Niazkar's [2] study, which consist of 2000 data points, were adopted. In this regard, 10 performance evaluation criteria were chosen from the literature [2]. These indices may be categorized into local and global criteria. The former includes (1) maximum Absolute Error (maxAE), (2) minimum Absolute Error (minAE), (3) maximum Relative Error (maxRE), (4) minimum Relative Error $(\min R E)$, (5) maximal positive Relative Error $(\max R E+)$ and (6) maximal negative Relative Error (maxRE-). On the other hand, the global criteria are (1) mean Absolute Error (meanAE), (2) mean Relative Error (meanRE), (3) Mean Square Error (MSE) and (4) standard deviation $\left(\Delta_{a v}\right)$. These indices are shown in Equations (4) to (7), respectively.

$$
\begin{gathered}
\text { meanAE }=\frac{1}{N} \sum_{i=1}^{N} \mid f_{i}^{\text {computed }}-f_{i}^{\text {Colebrook-White } \mid} \\
\text { meanRE }=\frac{1}{N} \sum_{i=1}^{N} \frac{\left|f_{i}^{\text {computed }}-f_{i}^{\text {Colebrook-White }}\right|}{f_{i}^{\text {Colebrook-White }}} \\
M S E=\frac{\sum_{i=1}^{N}\left(f_{i}^{\text {computed }}-f_{i}^{\text {Colebrook-White }}\right)^{2}}{N} \\
\Delta_{a v}=\sqrt{\frac{\sum_{i=1}^{N}\left(\frac{\left.f_{i}^{\text {Colebrook-White }-f_{i}^{\text {computed }}}\right)^{2}}{f_{i}^{\text {Colebrook-White }}}\right)}{N}}
\end{gathered}
$$

where $f_{i}^{\text {computed }}$ and $f_{i}^{\text {Colebrook-White }}$ are $f$ estimated by explicit equations and $f$ from the database, respectively, and $N$ is the number of data points.

\section{Results and Discussion}

The performances of the four models based on the mentioned local criteria are compared in Table 1. As shown, Model 3 improves the accuracy of Model 2 based on maxAE, maxRE, minRE and maxRE+, while it decreases the precision of Model 2 according to minAE and maxRE-. Furthermore, Model 4 improves the precision of estimating $f$ predicted by Model 2 based on all six criteria listed in Table 1 . In Table 1, the percentages of improvement vary from 1.48 up to 56.50 depending on the criteria, while the two percentages of accuracy reduction are $-44.81 \%$ and $-83.59 \%$ for $\operatorname{minAE}$ and $\operatorname{maxRE}-$, respectively. Among the four models compared in Table 1, Model 4 achieved the most accurate results based on four out of six local criteria. Finally, Table 1 indicates that the modified coefficients improve the accuracy of the original ones based on ten out of twelve compared values.

Table 1. Comparison of four explicit equations based on six local criteria.

\begin{tabular}{ccccccc}
\hline Models & $\operatorname{maxAE}$ & $\operatorname{minAE}$ & $\operatorname{maxRE}$ & $\operatorname{minRE}$ & $\operatorname{maxRE+}$ & $\operatorname{maxRE-}$ \\
\hline Model 1 & $1.01 \times 10^{-4}$ & $1.84 \times 10^{-7}$ & 0.1405 & $1.33 \times 10^{-3}$ & 0.1405 & 0.0107 \\
Model 3 (this study) & $9.29 \times 10^{-5}$ & $2.66 \times 10^{-7}$ & 0.1295 & $5.78 \times 10^{-4}$ & 0.1295 & 0.0196 \\
\hline Improvement (\%) & 7.81 & -44.81 & 7.81 & 56.50 & 7.81 & -83.59 \\
\hline Model 2 & $9.39 \times 10^{-5}$ & $1.69 \times 10^{-6}$ & 0.1309 & $8.40 \times 10^{-3}$ & 0.1309 & -0.0084 \\
Model 4 (this study) & $9.25 \times 10^{-5}$ & $1.30 \times 10^{-6}$ & 0.1290 & $6.94 \times 10^{-3}$ & 0.1290 & -0.0069 \\
\hline Improvement (\%) & 1.48 & 22.85 & 1.48 & 17.46 & 1.48 & 17.46 \\
\hline
\end{tabular}

Table 2 compares the performance of the four models in estimation of $f$ based on global criteria. As shown, the modified explicit equations outperformed the original ones as they improved eight pair-values compared in Table 2. According to Table 2, the percentages of improvement are placed 
within [1.74, 18.02]. Additionally, the percentages of improvement achieved by Model 3 are much more than those obtained by Model 4. Among the four models compared in Table 2, Model 3 yielded closer $f$ values than those obtained from the implicit Colebrook-White formula based on all four global criteria. Finally, Table 2 obviously demonstrates that the new coefficients proposed in this comment improve the accuracy of the original explicit equations based on global criteria considered.

Table 2. Comparison of four explicit equations based on four global criteria.

\begin{tabular}{ccccc}
\hline Models & meanAE & meanRE & MSE & $\boldsymbol{\Delta}_{\text {av }}$ \\
\hline Model 1 & $4.85 \times 10^{-5}$ & 0.1030 & $3.12 \times 10^{-9}$ & 0.1051 \\
Model 3 (this study) & $4.37 \times 10^{-5}$ & 0.0920 & $2.56 \times 10^{-9}$ & 0.0943 \\
\hline Improvement (\%) & 9.99 & 10.66 & 18.02 & 10.32 \\
\hline Model 2 & $4.68 \times 10^{-5}$ & 0.0972 & $2.99 \times 10^{-9}$ & 0.1004 \\
Model 4 (this study) & $4.60 \times 10^{-5}$ & 0.0953 & $2.89 \times 10^{-9}$ & 0.0986 \\
\hline Improvement (\%) & 1.74 & 1.98 & 3.13 & 1.81 \\
\hline
\end{tabular}

Niazkar [2] compared the performances of 18 one-step explicit equations for the same data, while the best ones are compared with the best of these four models (Model 1 to Model 4) in Table 3. The former explicit equations mentioned in Table 3 are presented in Appendix A. The comparison carried out in Table 3 shows how the best of the four models estimates $f$ in comparison to the best explicit equations available in the literature. As shown in Table 3, the value computed by each criterion is presented, while the corresponding explicit equation, which obtained each value, is mentioned in the parentheses next to each value. According to Table 3, nine out of 10 of the best models among the four models are those suggested in this comment, which shows that the modified coefficients recommended in this comment improves the original explicit equations based on nine out of 10 of the evaluation criteria considered. Furthermore, the best explicit equations reported in Niazkar [2] outperformed the best of the four models based on maxAE, minAE, minRE, maxRE+ and all of the global criteria considered. However, Model 4 reached to lower maxAE, maxRE and maxRE- than the best of 18 one-step explicit equations and the corresponding percentages improvement are $11.06 \%$, $69.43 \%$ and $94.39 \%$, respectively. Therefore, the modified coefficients in this comment bring about an improvement in terms of maxRE and maxRE- among all one-step explicit equations available in the literature. In conclusion, the new coefficients presented in this discussion considerably improve the accuracy of the estimation of $f$ obtained by the original explicit equations proposed by Brkić and Praks [1].

Table 3. Comparison of the best of four explicit equations with the best of 18 one-step explicit equations reported in Niazkar [2].

\begin{tabular}{ccc}
\hline Criteria & The Best Explicit Equations Reported in Niazkar [2] & The Best of the Four Models \\
\hline $\max A E$ & $1.4 \times 10^{-4}$ (Fang et al.) & $9.25 \times 10^{-5}$ (Model 4) \\
$\min A E$ & $1.25 \times 10^{-8}$ (Haaland) & $1.84 \times 10^{-7}$ (Model 1) \\
$\max R E$ & 0.422 (Fang et al.) & 0.129 (Model 4) \\
$\min R E$ & $3.72 \times 10^{-5}$ (Eck) & $5.78 \times 10^{-4}$ (Model 2) \\
$\max R E+$ & -0.0246 (Manadilli) & 0.129 (Model 4) \\
$\max R E-$ & 0.123 (Fang et al.) & -0.0069 (Model 4) \\
meanAE & $2.51 \times 10^{-5}$ (Fang et al.) & $4.37 \times 10^{-5}$ (Model 2) \\
meanRE & 0.0680 (Fang et al.) & 0.0920 (Model 2) \\
MSE & $8.35 \times 10^{-10}$ (Fang et al.) & $2.56 \times 10^{-9}$ (Model 2) \\
$\Delta_{a v}$ & 0.0856 (Fang et al.) & 0.0943 (Model 2) \\
\hline
\end{tabular}




\section{Conclusions}

The explicit equations are one of the most common approaches for estimating the Colebrook friction factor. In this regard, various studies have been conducted to develop an explicit equation, which yields much closer friction factors to the Colebrook-White formula. In this study, the coefficients of two explicit equations proposed by Brkić and Praks [1] were modified using powerful optimization algorithms. The performances of the modified explicit equations were compared with that of the original ones and 18 one-step explicit equations available in the literature. For comparing the performances, six local and four global indices were adopted from the literature. The obtained results indicate that the modified equations predict a more accurate Colebrook friction factor than the original ones based on nine out of the 10 criteria considered. This improvement in accuracy of estimation of friction factors is achieved without any additional computational costs.

Funding: This research received no external funding.

Conflicts of Interest: The author declares no conflict of interest.

\section{Appendix A}

The four explicit equations mentioned in Table 3 are presented in the following:

(1) Fang et al.'s [23] relation:

$$
f=1.613\left\{\ln \left[0.234\left(\frac{\varepsilon}{D}\right)^{1.1007}-\frac{60.525}{\operatorname{Re}^{1.1105}}+\frac{56.291}{\operatorname{Re}^{1.0712}}\right]\right\}^{-2}
$$

(2) Haaland's [24] relation:

$$
f=\left\{-1.8 \log \left[\left(\frac{\varepsilon}{3.7 D}\right)^{1.11}+\frac{6.9}{\operatorname{Re}}\right]\right\}^{-2}
$$

(3) Eck's [25] relation:

$$
f=\left[-2 \log \left(\frac{\varepsilon}{3.715 D}+\frac{15}{\operatorname{Re}}\right)\right]^{-2}
$$

(4) Manadilli's [26] relation:

$$
\left.f=\left\{-2 \log \left[\frac{(\varepsilon / D)}{3.70}+\frac{95}{\operatorname{Re}^{0.983}}-\frac{96.82}{\operatorname{Re}}\right)\right]\right\}^{-2}
$$

\section{References}

1. Brkić, D.; Praks, P. Accurate and efficient explicit approximations of the Colebrook flow friction equation based on the Wright $\omega$-function. Mathematics 2019, 7, 34. [CrossRef]

2. Niazkar, M. Revisiting the Estimation of Colebrook Friction Factor: A Comparison between Artificial Intelligence Models and C-W Based Explicit Equations. KSCE J. Civ. Eng. 2019, 23, 4311-4326. [CrossRef]

3. Niazkar, M.; Talebbeydokhti, N.; Afzali, S.H. Relationship between Hazen-William coefficient and Colebrook-White friction factor: Application in water network analysis. Eur. Water 2017, 58, 513-520.

4. Niazkar, M.; Talebbeydokhti, N.; Afzali, S.H. Novel grain and form roughness estimator scheme incorporating artificial intelligence models. Water Resour. Manag. 2019, 33, 757-773. [CrossRef]

5. Niazkar, M.; Talebbeydokhti, N.; Afzali, S.H. Development of a new flow-dependent scheme for calculating grain and form roughness coefficients. KSCE J. Civ. Eng. 2019, 23, 2108-2116. [CrossRef]

6. Niazkar, M.; Afzali, S.H. Analysis of water distribution networks using MATLAB and Excel spreadsheet: H-based methods. Comput. Appl. Eng. Educ. 2017, 25, 129-141. [CrossRef]

7. Niazkar, M.; Afzali, S.H. Streamline Performance of Excel in Stepwise Implementation of Numerical Solutions. Comput. Appl. Eng. Educ. 2016, 24, 555-566. [CrossRef] 
8. Niazkar, M.; Talebbeydokhti, N. Comparison of explicit relations for calculating Colebrook friction factor in pipe network analysis using h-based methods. Iran. J. Sci. Technol. Trans. Civ. Eng. 2020, 44, 231-249. [CrossRef]

9. Niazkar, M.; Afzali, S.H. Analysis of water distribution networks using MATLAB and Excel spreadsheet: Q-based methods. Comput. Appl. Eng. Educ. 2017, 25, 277-289. [CrossRef]

10. Brkić, D. W solutions of the CW equation for flow friction. Appl. Math. Lett. 2011, 24, 1379-1383. [CrossRef]

11. Brkić, D. Review of explicit approximations to the Colebrook relation for flow friction. J. Petrol. Sci. Eng. 2011, 77, 34-48. [CrossRef]

12. Brkić, D. Solution of the implicit Colebrook equation for flow friction using Excel. EJSIE 2017, 10, 4663.

13. Praks, P.; Brkić, D. Symbolic regression-based genetic approximations of the Colebrook equation for flow friction. Water 2018, 10, 1175. [CrossRef]

14. Sobol, I.M.; Turchaninov, V.I.; Levitan, Y.L.; Shukhman, B.V. Quasi-Random Sequence Generators; Distributed by OECD/NEA Data Bank; Keldysh Institute of Applied Mathematics; Russian Academy of Sciences: Moscow, Russia, 1992; Available online: https://ec.europa.eu/jrc/sites/jrcsh/files/LPTAU51.rar (accessed on 3 February 2020).

15. Niazkar, M.; Afzali, S.H. Assessment of Modified Honey Bee Mating Optimization for Parameter Estimation of Nonlinear Muskingum Models. J. Hydrol. Eng. 2014, 20, 04014055. [CrossRef]

16. Niazkar, M.; Afzali, S.H. Optimum Design of Lined Channel Sections. Water Resour. Manag. 2015, 29, 1921-1932. [CrossRef]

17. Niazkar, M.; Afzali, S.H. New Nonlinear Variable-parameter Muskingum Models. KSCE J. Civ. Eng. 2017, 21, 2958-2967. [CrossRef]

18. Niazkar, M.; Afzali, S.H. Application of New Hybrid Optimization Technique for Parameter Estimation of New Improved Version of Muskingum Model. Water Resour. Manag. 2016, 30, 4713-4730. [CrossRef]

19. Niazkar, M.; Afzali, S.H. Parameter estimation of an improved nonlinear Muskingum model using a new hybrid method. Hydrol. Res. 2017, 48, 1253-1267. [CrossRef]

20. Niazkar, M.; Afzali, S.H. Application of new hybrid method in developing a new semicircular-weir discharge model. Alex. Eng. J. 2017, 57, 1741-1747. [CrossRef]

21. Niazkar, M.; Afzali, S.H. Developing a new accuracy-improved model for estimating scour depth around piers using a hybrid method. IJST Trans. Civ. Eng. 2018, 43, 179-189. [CrossRef]

22. Niazkar, M.; Rakhshandehroo, G.; Afzali, S.H. Deriving explicit equations for optimum design of a circular channel incorporating a variable roughness. IJST Trans. Civ. Eng. 2018, 42, 133-142. [CrossRef]

23. Fang, X.; Xu, Y.; Zhou, Z. New correlations of single-phase friction factor for turbulent pipe flow and evaluation of existing single-phase friction factor correlations. Nucl. Eng. Des. 2011, 241, 897-902. [CrossRef]

24. Haaland, S.E. Simple and explicit formulas for the friction factor in turbulent pipe flow. J. Fluids Eng. 1983, 105, 89-90. [CrossRef]

25. Eck, B. Technische Stromungslehre; Springer: New York, NY, USA, 1973.

26. Manadilli, G. Replace implicit equations with signomial functions. Chem. Eng. 1997, 104, 129.

(C) 2020 by the author. Licensee MDPI, Basel, Switzerland. This article is an open access article distributed under the terms and conditions of the Creative Commons Attribution (CC BY) license (http://creativecommons.org/licenses/by/4.0/). 